\title{
ENGLISH AS SECOND LANGUAGE STUDENTS' STRATEGIES WHEN READING AND WRITING ABOUT LITERARY TEXTS: SOME ETHICAL CONSIDERATIONS
}

\author{
Khulekani Gazu \\ University of Zululand
}

\begin{abstract}
This study aimed to establish a substantive theoretical explanation from the ground to account for the experiences of some English as a Second Language (ESL) students when they read and subsequently write about literary texts. The target group of this grounded theory study comprised 34 university students enrolled for a degree in education majoring in English language and literature studies. Data were collected using the following procedures: unstructured interviews, structured interviews, focus group interviews and elicited document material. The data were analysed using the constant comparison method so that emerging codes, categories and subsequent themes were constantly saturated by collecting new data from the field. The findings established that some ESL students rely heavily on internet summaries and analyses of set works to mitigate the length of a literary text and the complexity of the language used - a practice that has both positive and negative ramifications. The positive ramifications include the provision of an entry point to a literary text; promotion of active reading by guiding the reading process; facilitation of the reading of long texts, like novels; and charting the landscape of a text. Negatively, the practice promotes a passive reading process, and it may replace the literary text. Reliance on the internet exposes students to the academically unethical practices of plagiarism and patch writing. Conversely, these practices are manifestations of language development among ESL students which can be exploited by lecturers as platforms where students appraise internet analyses of literary texts to render students' interpretive strategies ethical.
\end{abstract}

Keywords: plot navigation, lexical impoverishment, global text landscape, unethical practices

\section{INTRODUCTION AND BACKGROUND}

The study sought to establish English as a Second Language (ESL) students' experiences with literary texts as told from their own perspectives. The researchers observed that when students enrol at a university, the assumption is that they are competent readers and speakers based on the English mark they obtained in their Senior Certificate, without due consideration of the level of sophistication or complexity at which an additional language is offered. At the university level, there is no distinction between first and second language. What cannot be overlooked, is that some ESL students' English competence is not comparable to that of their 
native counterparts. A commonly held view in the study and assessment of literary texts is that students must reflect originality of thought in response to questions on literary texts. Ideally, the responses should be free of rehashed interpretations that are barren of deep engagement and scholarly insight; in instances where secondary critical readings are consulted, these should augment students' ingeniousness. Worthy of note, however, is the observation that inadequate emphasis is placed on the reader who reads literary texts that are not written in his or her native language, that is, a second language speaker of English, in this case.

While it must be admitted that the ability to read in one's first language should serve as an advantage when a student is confronted with a text written in a second language, there are likely to be some shortcomings that emanate from the fact that one is not reading in one's first language, which is the language of thought. Cunningham (2005) states that first language reading commences when at least 5000 words have already been acquired. On the other hand, second language readers have to grapple with unfamiliar vocabulary and syntactic structures with which they are not comfortable. Worthy of note is that, while first and second language readers may not be on the same level, the latter vary greatly in terms of age, intellectual capacity, personality and other factors; they are not a homogeneous group. There are even first language speakers who struggle with literary texts. Hasim and Din (2009: 127) argue that ESL learners' reading of literary texts is slowed down by 'linguistic complexity, lack of cultural background knowledge of the text, length of text, texts that are not suitable, as well as students' lack of vocabulary'. Ahmad and Aziz (2009: 19) argue that ESL students have to contend with the complexity of the content and style of literary texts, as well as 'linguistic and aesthetic unfamiliarity'.

Other studies have focused on the reading strategies of ESL students. For example, studies on literary competence aver that engagement in literary studies presupposes adequate reading skills - skills like word recognition and working out the meanings of words, which is a cognitive function (Urquhart \& Weir, 1998). Grabe and Stoller (2002), Anderson (2007) and Wallace (2003) take the argument further by positing that literary texts need to be interpreted, comprehended and critiqued; therefore, students are assumed to be equipped with these skills when they undertake literary studies. For Bouazid and Le Roux (2010), learning to read happens once - usually in the first language; therefore, reading in a second language requires the extension of the same literacy. What compounds the challenge of second language reading is the process of meaning-making. Khanam, Zahid and Mondol (2014: 83), with reference to the schema theory, postulate that 'EFL readers construct meaning from clues found in a text which is related to the use of background knowledge in understanding the content of the written pages'. The critical point to note is that meaning is socially constructed; therefore, whatever the student reader knows is a reflection of the cultural norm of his or her society. Khanam et al. (2014) further contend that, if the second language text is interpreted by making use of the existing framework of knowledge, there is bound to be a conflict between the sociocultural context of the reader and the context of the second language text, thus complicating the interpretation and comprehension. Concerning the schema, Bouazid and Le Roux (2010: 35) state that 'reading comprehension ... depends on the reader being able to relate information from the text to pre-existing knowledge'. What can be gleaned from the foregoing literature is the problemof incompetent readership manifesting in the lack of interpretation, comprehension and critiquing skills. An ideal reader should possess the requisite literary competence prior to the process of reading. Since the ideal reader norm cannot always be assumed as extant, especially where reading happens in a second language, this study sought to elicit the perspectives of these readers about their experiences of reading. 
The study adopted an emergent design, commencing with generic questions and building on the responses from the participants. None of the reviewed studies adopted the grounded theory approach. Therefore, this study challenged the notion of an assumed competent reader in the context of ESL students by advocating alternative views emanating from students' voices.

\section{RESEARCH OBJECTIVES AND QUESTIONS}

The study aimed to generate a substantive theoretical explanation of how ESL students engage with literary texts during the reading phase and, subsequently, during the writing phase. The objectives of the study were to establish the nature of the experiences which ESL students undergo when reading and writing about literary texts, explain how ESL students experience the process of reading literary texts and provide reasons why ESL students experience the literary texts the way they do. The said objectives were achieved through the following questions: What are ESL students' experiences with literary texts? How do ESL students experience literary texts? Why do ESL students experience literary texts the way they do?

\section{THEORETICAL FRAMEWORK}

\section{Reader-response theory}

The study was underpinned by the tenets of reader-response theory as gleaned from Bressler (2003: 62), which seek to answer the question: 'What is and what happens during the reading process?' The tenets include that 1) 'the reader has to be seen not only as the person reading, but also his or her world knowledge, background, viewpoint, reason for reading, and knowledge of words and literature must be taken into account' and 2) 'meaning has to be regarded from the interaction or transaction between the reader and the text'. These tenets helped to locate the study within the variables of the reader (students), the text and the dynamics involved in the reading of literary texts. These variables are built into the research questions and objectives.

\section{METHODOLOGY}

\section{Research design}

The study employed a qualitative research design using grounded theory as propounded by Strauss and Corbin (1990). Creswell (2007) points out that participants in this design must have experienced the process and the development of the theory that helps explain practice or provide a framework for further research. In this study, the researchers attempted to generate a general explanation or theory of the process involved in the students' engagement with literary texts.

\section{Sampling}

The sampling strategies that were employed in the study were purposive sampling and theoretical sampling. These strategies were employed in a sequence; each step yielded a new set of questions emanating from the emerging understanding towards the saturation of the phenomenon. The objective was to shed more light on the target group, not to generalise. Charmaz (2006) recommends that the sample in grounded theory should comprise 20 to 30 individuals in order to develop a well-saturated theory. However, the number is not 
prescriptive. In this study, 11 participants (five for interviews and six for elicited documents) were selected during the purposive sampling stage. During the subsequent theoretical sampling, 23 more participants were selected - of these, nine were subjected to intensive interviews as individuals while three wrote elicited documents, and the other 11 were part of the focus group interview. The participants were education students doing English language and literature at the third-year level. All of them were second language speakers of English who had done English at second language level in their high school education. In terms of gender, there were 28 female and six male participants.

What informed the purposeful selection of participants was that the research population mainly comprised first-, second- and third-year students. The first- and second-year students of literature were generally not selected for the study, as they were deemed not to be adequately experienced in the phenomenon under investigation. The third-year students were targeted because they had studied all the genres (poetry, short stories, novels and plays) for almost three years, excluding their high school years. Therefore, these were participants who would be in a better position to relate their experiences with regard to studying literature. Theoretical sampling was adopted as the level of analysis was becoming more abstract than verbatim. The focus group enabled theoretical saturation by diversifying properties and dimensions. 'Theoretical sampling regards the process of data collection, where new targets for data collection are directed by the results collected from the preceding sample' (Jones, Kriflik \& Zanko, 2005).

The target group comprised university students enrolled for a degree in education, majoring in English language and literature studies. The module was offered by the Department of English in the Faculty of Arts. The sampled members of the population had done English at second language level in their matriculation. The dominant language of communication for most students in the university was isiZulu. Even students for whom isiZulu was not a vernacular language still used it in residences and other social spaces. All students were able to access internet facilities, which are mediated through English. Even though English was used across the student population, it was not as dominant as isiZulu. Students were in contact with the English language, particularly during lecture time and when writing different assessment tasks. The average number of students registered for English 3 in a given year is 120.

\section{Data collection}

The researchers carried out data collection using the following procedures: unstructured interviews, structured interviews, focus group interviews and elicited document material. The interviews ran parallel with the writing of elicited material. Unstructured interviews collected data for open coding. The subsequent interviews collected data for axial and selective coding.

\section{Unstructured interviews}

The researchers first conducted interviews for the purposive sample. Unstructured, openended interviews were initially administered to the individual participants to collect their views on the phenomenon. The rationale behind the open-endedness of the interviews was that it allowed the participants to express their experiences without too much interference from the researchers. In this way, a degree of validity of the instrument was ensured, and participants could express themselves in their own words as far as possible. 


\section{Structured interviews}

Structured interviews were employed during theoretical sampling because the initial understanding of the phenomenon had already been established. Having established what the students' experiences were through the open-ended questions, more structured interviews were subsequently conducted. This was necessitated by the fact that a more intimate understanding of the emerging phenomena was needed. Structured questions were coined from the initial responses of the participants. These questions emerged during the process of memo writing, which was accompanied by the diligent exercise of the constant comparison method being applied to the data (interview transcripts and elicited material). The focus group interviews were the last to be conducted, with the view to attain theoretical saturation.

\section{Elicited document material}

The researchers purposively selected six participants to express in writing their experiences with literary texts. They were given the same guiding questions asked during interviews to respond to, but the researchers did not supervise the writing process. In essence, the participants expressed themselves without the interference of the researchers. Instead, they had the liberty to respond during times that were convenient for them. This was meant to eliminate the authority of the researchers. It was also meant to diversify the tools of data collection so that there would be no heavy reliance on the interviews. Thus, the elicited material brought about the reliability of the instruments and the validity of the responses. The same procedure was followed during theoretical sampling, where the elicited material was sourced from three participants in response to emerging questions.

\section{RESULTS}

The constant comparison method of data analysis was carried out with each successive phase of data collection. Three phases of data coding were undertaken, namely, open coding (with the attendant early memo), axial coding (accompanied by intermediate memos) and selective coding (with the attendant advanced memos). Saldana (2013:3) defines a code as 'a word or short phrase that symbolically assigns a summative, salient, essence-capturing and/or evocative attribute for a portion of language-based or visual data'. The researchers wanted to avoid a certain degree of personal bias which could result from extrapolating from the data what was not an accurately expressed lived experience. Therefore, pursuant to the latter objective, in vivo codes were utilised during open coding. Saldana (2013: 91) defines in vivo as 'in that which is alive', so this coding is perceived as 'inductive coding' as it moves from that which is particular or specific.

The second coding step in grounded theory as advocated by Strauss and Corbin (1990) is axial coding. In this process, the data initially broken into pieces during open coding are rearranged in other ways with the view to shed more light on the properties and dimensions of each category. During data analysis (essentially an intertwined process of data collection, open coding, writing of analytical memos as well as the subsequent theoretical sampling, selective coding, etc.), the themes in the paragraphs below emerged about the role played by the internet summaries and analyses in the study of literary texts by ESL students. The salient category that emerged from the data was students' reliance on websites, such as Shmoop and Sparknotes, that offer notes on plot summary, character analyses, themes, setting and motifs. The dimensions to the category are set out below. 


\section{Provision of an entry point to a literary text}

The internet summaries and analyses are capable of organising a text, especially a novel, by providing an entry point to the text. The entry point is provided by the internet's creation of an expectation prior to the reading process. One participant alluded to the role of the internet as 'tell[ing] you what to expect from the book'. It is apparent that the correct 'expectation' demystifies the difficulty or complexity of the text in the cognitive domain.

\section{Mediation of the reading process}

The internet summaries and analyses mediated the reading process, as one participant stated: 'Sparknotes tell you more' (KG125). The phenomenon of relying on the internet seemed to be entrenched, as some users were aware of the underlying danger. To this end, participants warned against the use of the internet when it came to poetry: the internet is 'not wise with poetry' (KG87) and 'do not depend on the internet for poetry'. This is an indicator that students use internet services with some discrimination. It may be summarily deduced that the internet assists in the understanding of literary texts and facilitates the reading process in different ways. If it offers the analysis of texts through a logical breakdown of the text into plot and themes, the students who rely on the internet understand better when they build their insight from the component parts and then proceed to the whole. The component parts are simpler to process cognitively. Therefore, the internet plays an interventionist role, and for some students, the manipulation of the service has become a norm: 'I go to the internet ... most of the time' (KG67). Participant 19 captured it perfectly:

The internet plays a big role because there you get many websites and then you get different views of different people. And then you formulate your own ideas or your own analysis based on those because sometimes you read the text you don't even understand what it is about. There you get summaries, you get character analysis, and you [are] able to formulate your own analysis based on that. It is very useful (codes 384, $385 \& 386$ ).

\section{Promotion of active reading}

One can glean from the responses that the internet holds the power to promote more active reading as it guides the reading process. This results in a more informed readership, which should spur on the reader until the text has been completed. One can also conjecture that the internet bridges the knowledge gap and thus empowers the reader's predictive reading skills. In such a situation, cognitive processes must be at their utmost, and the kind of questions that the reader is asking him- or herself must be of a higher order. Participant 16 averred:

You know sometimes most students ... we are (laughing) they are very lazy in reading the whole text. So when you go to the internet it gives us a bit of an idea of what the text is about. So when the summary is good, it makes you wanna read the text. And some of the things they highly ... you wanna go more ... you wanna like go deeper in the text, read it on what they were talking about - something like that (codes 372, 373 $\& 374)$.

Internet summaries and analyses facilitate the reading of long texts, like novels. In the light of the time required to finish a long novel that was prescribed for the English course, Participant 12 stated that 
the internet ... help[s] students to understand these long texts; should it happen that I do not understand the text after I have read it, then I consult the internet for the summary of the internet and other analyses of the text (codes $357 \& 358$ ).

Not only does the internet intervene when it comes to the length of the text, but it also assists in enhancing the comprehensibility of the text. In this light, Participant 18 stated:

Yoooh [the] internet plays a very major role because it gives us a lot of summaries when you read that text. Sometimes not all the texts are easy to understand, so when you visit that website you find some summaries and then get to understand this text is about this thing (codes $378 \& 379$ ).

\section{Charting the landscape of a text}

Internet summaries and analyses chart the landscape of a text. Most notable for this was Participant 16, who hinted at a cognitive aspect: 'It gives us a bit of an idea of what the text is about' and thus not only creates an expectation, but the participant also believed that 'when the summary is good, it makes you want [t] to read the text' (code 373). A reaffirmation of the indispensability of the internet analyses is captured in the words of Participant 21: 'Hey, we are about to graduate and without the internet, my God, I don't know what we would be [laughing aloud]. I don't know what we would be.' This sentiment was later reiterated in the focus group as: 'If it wasn't for Sparknotes, I wouldn't be doing Level 3' (FINAL 85).

\section{Promotion of a passive reading process}

On the flip side, however, reliance on the internet can promote a passive reading process. When the reader makes no conjectures while reading a literary text, the discovery element is taken away from the text. The reader who has read notes from the internet before engaging with a literary text is susceptible to derive less aesthetic value from a text. By its very nature, a literary text is meant to be appreciated for its artistic quality. If it is devoid of the artistic touch, it loses its essence. The resultant inactivity of the reader has adverse effects on the reading process, and it is counterproductive. Participant 12 acknowledged the extensive use of the internet and its negative impact:

It should be noted that I personally do not rely on the internet for my assignments because that promotes passiveness and dependency. The internet should be the guideline not the only way to go. However, in this decade most students find it easier to use the internet than the textbooks for their assignments (codes 359, 360 \& 361).

\section{Replacement of the literary text}

Some students appeared to have adopted internet summaries and analyses as a replacement for the text. That is, they read the summaries having not read the text at all. The practice of replacing the text with internet summaries and analyses is negative in itself. Moreover, there were specific reasons put forth by students for considering it as such. Participant 12 pointed out that they did 'not rely on the internet for assignments because that promotes passiveness and dependency' (Code 359). Participant 13 believed that

the internet does not play much of a role; instead, it puts most of us in jeopardy of being penalised for plagiarism. It does help though, only if it is used in the right manner. That is, acknowledging the sources used (Code 362). 
In a nutshell, the above results address the first and the third questions by portraying that the salient experience of ESL students is that they find literary texts linguistically complex and lengthy, such that they require internet sources which provide an entry point to the text. The second question is how students experience literary texts. This is answered by how students' use of internet sources helps them mediate the reading process, chart the landscape of a text and promote active reading. The strategy of using internet summaries and analyses is also fraught with unethical practices when it promotes a passive reading process and when it replaces the literary text, thus resulting in plagiarism. These results resonate with readerresponse theory as they reflect the actions of the reader and the difficulties presented by the text; therefore, students' actions are part of a transaction towards meaning making. In the next sections, the results surrounding learners' experiences are discussed in light of the ethics of using internet sources without following the academic writing conventions, for example, plagiarising. Another dimension will be to consider how lecturers as assessors of literary texts can adapt to the ESL students' language development phase manifesting as internet plagiarism in order to exploit the electronic avenues available for the benefit of students.

\section{DISCUSSION}

The guiding questions in the identification of the central phenomenon, according to Strauss and Corbin (1990: 100), are as follows: What is this data referring to? What is the action/interaction all about? The central phenomenon which became clear in this study is that some ESL students struggle during the process of reading and subsequently writing about literary texts, so much so that they have to rely on sources peripheral to the literary text being read. This conclusion was drawn from the themes presented in the previous section.

The causal conditions are as follows: Language difficulty in a literary text, tied with the relative lexical impoverishment of some ESL students, is responsible for some students struggling with literary texts. This finding is consistent with Hasim and Din (2009), particularly on the issues of 'linguistic complexity' and 'lack of vocabulary'. Similarly, Tevdovska (2016) alludes to the fact the language of literature is unique. The length of a text, such as a novel, adversely affects some ESL readers as they fail to read the text to completion in good time to be ready for assessment. The length of the text combined with less reading time available sometimes results in a loss of plot navigation, a situation that obtains when, due to the extended period of time of reading a text, the reader ends up forgetting those parts or events that have already been read in a lengthy literary text. This finding is partly akin to Tevdovska (2016: 164), who avers that 'there are several problems of practical nature when dealing with novels, among them the length of novels probably being the most common one.'

One salient interactional strategy that emerged was the students' reliance on the internet summaries and analyses to mitigate the length of text. Participants surfed Shmoop, Sparknotes and other websites which offer detailed analyses of a specific work of literature, including plot summary, character analyses, themes, setting (the spatio-temporal situation), motifs, and other pertinent theoretical and critical issues. The phenomenon of relying on the internet may be regarded as orthodox where peer-reviewed resources are accessed, acknowledged and critiqued. However, what stands out in this study is that the practice overshadows the everyday literary engagement as it offers depth beyond what normally obtains in a lecture room. Worthy of note is that the discipline of literary studies purports to entrench creative reasoning, not 'answers' which students surf for. This phenomenon of using the internet analyses intertextually with the novel has parallel features with Irrazabal, Saux, Barreyro, Burin and Bulla (2015), who found that the comprehension of expository digital 
texts can be facilitated by the hypertext, designed as an active reading strategy. Klois, Segers and Verhoeven (2013) arrived at a similar conclusion about hypertexts. Similarly, Chen and Chen (2014) posit a collaborative reading annotation system as advantageous to comprehension.

The contextual condition in which the phenomenon is located is reading texts with the view to offer a sound interpretation. The essence of literary studies is not to remember events and incidents in the plot, but to judge and interpret causality, character, and social issues emanating from themes, as well other literary conventions or theories.

Two intervening conditions constrain the strategy of using internet summaries and analyses. First, internet summaries treat peripheral content; hence, there is a lack of depth in literary engagement. Second, the use of the internet without proper acknowledgement (which is predominantly the case in the study) adversely affects the didactic relationship between students and lecturers when it comes to assessment. The former condition is relevant in highlighting that the summary cannot replace the literary text because it lacks the necessary depth of event and setting description - a requirement likely to be assessed by lecturers. The latter one underscores the practice of plagiarism, which presents a moral or ethical dilemma when students are assessed since assignments and examinations require an original engagement with and interpretation of a literary work. The requisite literary interpretation is relegated to the periphery, and instead, imported interpretations become central. In the researchers' observation and experience with undergraduate students, many of them do not see the practice as unorthodox at times, especially if they learn the internet analyses off by heart and later regurgitate them during examinations. In the process, the relationship between students and lecturers is affected as students feel that they are unduly penalised. On the other hand, the intervening conditions that facilitate reliance on internet summaries and analyses include that they ease literary interpretation and break down the plot, thereby facilitating the reading of a long text.

Consequences come about as a culmination of the interactional strategy, that is, relying on the internet summaries and analyses in this case, as well as other conditions surrounding it. The internet has both positive and negative ramifications for reading and writing (assessment) about literary texts. At one level, it provides an entry into the text. In other words, whether used before or after reading the text, the internet summaries and analyses mediate the reading process by locating the different avenues within the text that can be explored by the reader. This reverses the loss of plot navigation created by the length of the text; instead, the internet summaries and analyses offer a global landscape of the text in the sense that all aspects of the plot can be readily accessed before the actual text is read. Even a text that was read a while back can be revisited in its entirety in terms of both the plot and interpretation. It also creates an expectation for the reader prior to engaging with the literary text and activates the necessary past experiences or schemata for more meaningful engagement and interpretation. Arguably, the reader will be more informed of the global landscape of the text before the actual process of reading. Such a reader becomes more active because barriers to comprehension will have been removed; therefore, he or she will not just focus on the plot, but will be more analytical at the same time. The length factor of the novel will have a lesser bearing on the reader's fluency. At another level, knowing all the avenues for exploration within a text may yield passive reading as one will not attempt to form conjectures of what is likely to follow in the plot line, thereby resulting in boredom and lack of interest. The text loses its aesthetic value to such a reader. This finding is consistent with Roynon's (2014) 
objection to Toni Morrison's writing her own foreword to her novels as undermining the authority of the reader.

In light of the foregoing, it is therefore imperative to consider different views on plagiarism. Among academic transgressions in institutions of higher learning, plagiarism features very prominently (Breen \& Maassen, 2005; McCabe, 2005; Selwyn, 2008). One perspective holds that plagiarism is an academically unethical practice. For example, Ison (2012) avers that it is a violation of rules and received standards, and therefore it receives attention from researchers on cheating and academic ethics. The practice is attributed to different circumstances. For example, Breen and Maassen (2005) suggest that students fail to paraphrase and consequently resort to plagiarism, even though they know it is wrong. Another view is that plagiarism is caused by the inability to properly cite, especially when working under pressure (Breen \& Maassen, 2005; DeVoss \& Rosati, 2002; Eret \& Gokmenoglu, 2010).

A slightly different perspective is that second language students revert to patch writing as a strategy to shift attention from their lack of language competence by misappropriating fragments of the original work (Starfield, 2002). In second language writing research, patch writing is viewed in the light of a writer's development and language skills (Pecorari \& Petri'c 2014). In other words, incorporating strands of other texts in one's writing is seen as a developmental stage towards the attainment of more advanced language writing skills. The same sentiment is held by Howard (1995), who regards plagiarism as a specific form of language use, a feature which characterises a stage of language development. A related perspective is held by Tufescu (2008), who regards it as a literary phenomenon manifesting itself as one type of intertextuality influenced by Bakhtin's dialogic nature of language: writing is intertextual as it implicitly or explicitly contains strands of other texts.

\section{CONCLUSIONS}

From the foregoing discussion, it is evident that internet plagiarism is viewed chiefly as an academic transgression. The alternative view is that it is a manifestation of language development, especially among ESL students. The paper explored the alternative view further by extending the boundaries of our understanding of internet plagiarism. It pointed out both the positive and the negative offshoots derivable from students' use of internet sources while reading and when being assessed on literary texts. While the practice of relying on internet summaries and analyses may be considered unethical by assessors (lecturers, in this case), it must be viewed in context for some ESL students. These students employ it as a strategy to gain access to a literary world which they are denied by their relative language incompetence.

It is recommended that the assessment of literary texts should be conducted with due consideration of the multiplicity of centres of knowledge available in this information age. Manifestations of language development like the use of internet summaries and analyses towards literary competence must be harnessed and channelled into a more original literary engagement to avoid the unethical act of plagiarising internet sources. For example, students could be instructed to critique a literary interpretation offered by a specific website on a particular work so that they realise that literary interpretations are determined by different communities of readers. With the advent of the fourth industrial revolution and the COVID19-imposed e-learning era in higher education, the internet is so indispensable that literary studies lecturers need to plan assessment activities around it. In order to instil ethical practices among students, lecturers' assessment strategies must adapt to the techno- 
ecosystems of the students who produce literary interpretations. Students' schemata, and hence their literary interpretations, are shaped by their environments as digital natives; therefore, literary assessments should challenge their higher cognitive engagement with their worlds. Demonstrably, reader-response theory has cast attention on these students' decoding strategies - irrespective of the perceived lack of ethics of such strategies. The theory has cast light on the relationship between the reader and the literary text; consequently, it emerges from this study that this relationship can be threefold as the internet summaries and analyses offer the mediation. This paper offers a reader-internet-text model to Bressler's (2003) question about what happens during the process of reading. In a nutshell, the research questions have been addressed by the finding that the internet analyses demystify the complexity of the text by creating an expectation prior to the reading process.

\section{REFERENCES}

ABASI, A R \& N AKBARI. 2008. Are we encouraging patch writing? Reconsidering the role of the pedagogical context in ESL student writers' transgressive intertextuality. English for Specific Purposes, 27(3): 267-284.

AHMAD, F \& J AZIZ. 2009. Students' perception of the teachers' teaching of literature communicating and understanding through the eyes of the audience. European Journal of Social Sciences, 7(3): 17-26.

ANDERSON, NJ. 2007. The role of metacognition in second language teaching and learning. In Kerka, S. (ed), What works? Study skills. Columbus: Ohio State University.

BOUAZID, T \& CS LE ROUX. 2010. Constraints experienced by EFL literature students: A case study from an Algerian university. Per Linguam, 26(2): 33-49.

BREEN, L \& M MAASSEN. 2005. Reducing the incidence of plagiarism in an undergraduate course: The role of education. Issues in Educational Research, 15(1): 1-16.

BRESSLER, C. 2003. Literary criticism: An introduction to theory and practice. New Jersey: Prentice Hall.

CHARMAZ, K. 2006. Constructing grounded theory. London: SAGE Publications Ltd.

CHEN, C \& F CHEN. 2014. 'Enhancing digital reading performance with a collaborative reading annotation system'. Computers \& Education, 77: 67-81.

CRESWELL, JW. 2007. Qualitative inquiry and research design: Choosing among five approaches. $2^{\text {nd }}$ Ed. Thousand Oaks: Sage Publications.

CUNNINGHAM, AE. 2005. Vocabulary growth through independent reading and reading aloud to children. In Hiebert, HE \& ML Kamil (Eds.), Teaching and learning vocabulary: Bringing research to practice. Mahwah: Lawrence Erlbaum Associates Publishers. 45-68.

De VOSS, D \& A C ROSATI. 2002. 'It wasn't me, was it?' Plagiarism and the web. Computers and Composition, 19(2): 191-203.

FISH, S. 1980. Is there a text in this class? The authority of interpretative communities. Cambridge: Harvard University Press.

GRABE, W \& FW STOLLER. 2002. Teaching and researching reading. Harlow: Pearson.

HASIM, Z \& N DIN. 2009. 'Exploring ESL learners' reading strategies in understanding literary texts'. E-Proceedings of The International Online Language Conference (IOLC), pp. 112-129.

HOWARD, RM. 1995. Plagiarisms, authorships, and the academic death penalty. College English, 57(7): 788-805.

IRRAZABAL, N, G SAUX, J BARREYRO, D BURIN \& J BULLA. 2015. 'La comprensión del texto digital expositivo en el aula virtual de aprendizaje'. Perspectivas En Psicología: Revista De Psicología Y Ciencias Afines, 12(2): 57-66.

ISON, DC. 2012. Plagiarism among dissertations: Prevalence at online institutions. Journal of Academic Ethics, 10(3): 227-236.

JONES, ML, G KRIFLIK \& M ZANKO. 2005. Grounded theory: A theoretical and practical application in the Australian film industry. In A Hafidz Bin Hj (Eds.), Proceedings of 
International Qualitative Research Convention, 2005, (QRC05). Malaysia: Qualitative Research Association of Malaysia.

KHANAM, M, M ZAHID \& M MONDOL. 2014. 'The role of schema for effective EFL reading comprehension'. ASA University Review, 8(1): 83-93.

KLOIS, S, E SEGERS \& L VERHOEVEN. 2013. 'How hypertext fosters children's knowledge acquisition: The roles of text structure and graphical overview'. Computers in Human Behavior, 29(5): 2047-2057.

LOGUE, R. 2004. Plagiarism: the internet makes it easy. Nursing Standard, 18(51): $40-43$.

McCABE, D. 2005. Cheating among college and university students: A North American perspective. International Journal for Educational Integrity, 1(1): 1-11.

PECORARI, D \& B PETRI'C. 2014. Plagiarism in second-language writing. Language Teaching, 47(3): $269-302$.

PERRY, B. 2010. Exploring academic misconduct: Some insights into student behaviour. Active Learning in Higher Education, 11(2): 97-108.

PINNEGAR, S \& J DAYNES. 2007. Handbook of narrative inquiry: Mapping a methodology. Thousand Oaks, CA, US: Sage Publications.

ROYNON, T. 2014. 'Lobbying the reader: Toni Morrison's recent forewords to her novels'. European Journal of American Culture, 33(2): 85-96.

SALDANA, J. 2013. The coding manual for qualitative researchers. $2^{\text {nd }}$ Ed. London: SAGE Publications Ltd.

SELWYN, N. 2008. 'Not necessarily a bad thing . . . ': A study of online plagiarism amongst undergraduate students. Assessment and Evaluation in Higher Education, 33(5): 465-479.

SNAPPER, G. 2009. Beyond English literature A level: The silence of the seminar? A study of an undergraduate literary theory seminar. English in Education, 43(3): 192-210.

STARFIELD, S. 2002. 'I'm a second-language English speaker': Negotiating writer identity and authority in Sociology One. Journal of Language, Identity, and Education, 1(2): 121-40.

STRAUSS, A \& L CORBIN. 1990. Basics of qualitative research: Grounded theory procedures and techniques. California: SAGE Publications, Inc.

TEVDOVSKA, EL. 2016. Literature in ELT setting: Students' attitudes and preferences towards literary texts. International Conference on Teaching and Learning English as an Additional Language. Procedia - Social and Behavioral Sciences, 232: 161 - 169.

TUFESCU, F. 2008. Oscar Wilde's plagiarism: The triumph of art over ego. Dublin: Irish Academic Press.

URQUHART, S \& C WEIR. 1998. Reading in a second language: The process, product and practice. London: Longman.

WALLACE, C. 2003. Critical reading in language education. New York: Palgrave Macmillan.

\section{BIOGRAPHICAL NOTE}

Khulekani Gazu is a lecturer in the University of Zululand where he lectures English in the Department of Arts and Languages Education in the Faculty of Education. His research foci include English literature in education and second language learning. His fields of interest lie in empirical literary studies, language teaching and discourse analysis. 